\title{
Effectiveness of Breathing as a Non-Pharmacological Method to Reduce Pain Severity among Woman During Labor
}

\author{
Nawras Monim Alzurfi ${ }^{1}$, Shukriyia Shadhan Al-Ogaili \\ ${ }^{1}$ Research Scholar, Maternity Department/Faculty of Nursing/University of Kufa, Iraq, \\ ${ }^{2}$ Professor, Health and Medical College Techniques, Al-Furat Al-Awsat Technical University, Iraq
}

\begin{abstract}
The aim of the study is identify the effect of non-pharmacological method technique (breathing) on severity of pain through comparing woman's pain score during labor.A quasi-experimental Design is used through the present study in order to achieve the study objectives. The period of the study is from 15th January to 4th June 2020. A Non-Probability (Purposive Sample) of (60) women (30) of them are control group and (30) women are the study group, selected from those who are admitted to Al-Zahraa Maternity Teaching Hospital/ Al-Forat Teaching Hospital, are included in the study sample. Labor pain was assessed using the scale known as: Face, Leg, Activity, Cry, And Consolability (FLACC). Breathing Technique was used as a nonpharmacological method to reduce pain . The current study revealed that applying the non-pharmacological pain managing interventions (breathing) showed a remarkably significant reduction in pain according to in FLACC behavioral scale regarding the other stages (active phase (after intervention); transition phase; second Phase; third Phase) which. . It is concluded that breathing has reduced pain during active phase, transition phase, and second phase .
\end{abstract}

Keywords: Breathing, Non-Pharmacological, Pain Severity, Woman Labor.

\section{Introduction}

Women often mention, that because of their anxiety they would prefer a caesarean section rather than a natural delivery ${ }^{(1)}$. Occasionally, women feel little if any pain in labor and give birth unexpectedly ${ }^{(2)}$. Labor pain has its two elements: visceral and somatic. The visceral one occurs during the first stage of labor and it is connected with the tension exerted on the cervix, which causes its dilatation. That is felt by a parturient as a pain. The somatic kind of pain appears at the end of the first stage and it lasts also in the second stage. It is a result of the force exerted on the vaginal part of the cervix, the vagina and the perineum ${ }^{(3)}$. Labor pain management is not only a crucial concern for

\section{Corresponding Author:}

Nawras Monim Alzurfi

Research Scholar, Maternity Department/Faculty of

Nursing/University of Kufa, Iraq

e-mail: nawrasm.alzurfi@student.uokufa.edu.iq future mothers but also a great challenge in modern medicine. A wide range of both pharmacological and non-pharmacological labor pain relief techniques are currently available for pregnant women in Poland. The first group includes: epidural analgesia, gas for pain control and intravenous opioids. Non pharmacological techniques contain water birth and water immersion, transcutaneous electrical nerve stimulation (TENS), aromatherapy, acupuncture and acupressure, massage techniques ${ }^{(4)}$. In general, labor pain management means use complementary and alternative medicine (CAM) that includes herbs, vitamins and minerals, massage, aromatherapy, acupuncture, homeopathic remedies as well as psychological, physical and spiritual techniques. Its prevalence is increasing in developed countries likewise in the united states of America (USA) used by more than one third of pregnant women, while in the united kingdom (UK) used by $(57.1 \%)$ of women during pregnancy . In Arab countries, it is used by $(40.0 \%)$ in Palestine, $(75 \%)$ in Jordan, and $(22.3 \%)$ in Iran. However, women in Iraq are little is known about the use of pain management during labor ${ }^{(5)}$.TO identify the effect of non-pharmacological method technique 
(breathing, back massage) on severity of pain through comparing woman's pain score after the application of these method. The aim of the study is identify the effect of non-pharmacological method technique (breathing) on severity of pain through comparing woman's pain score after the application of these method .

\section{Method}

A quasi-experimental Design is used through the present study in order to achieve the study objectives. The period of the study is from 15th January to 4th June 2020.

A Non-Probability (Purposive Sample) of (60) women (30) of them are control group and (30) women are the study group, selected from those who are admitted to Al-Zahraa Maternity Teaching Hospital/Al-Forat Teaching Hospital, are included in the study sample.

Part 1: Demographic Data: A demographic data sheet, which consists of (6) items, include: Age, level of education, monthly income, occupational status of wife, occupational status of the husband, and resistance environment.

Part 2: Reproductive Health Data: The second part of the questionnaire is comprised which including expected date of delivery, history of current labor, gestational age, uterine contraction, duration and frequencies), membrane status for each stage.

Part 3: Pain Assessment (FLACC behavioral Scale): This scale has been constructed to assess the labor pain in a behavioral pain scale (Face, Leg, Activity, Cry, And Consolability (FLACC). It includes five categories ranged from 0 to 2 scale, which results in a total score of $0-10,(0=$ relax and comfortable, $1-3=$ mild pain, $4-6$ moderate pain, $7-10=$ sever pain).

Part 4: Breathing Technique was used as a nonpharmacological method to reduce pain.

Statistical Analysis: Descriptive statistics presented as mean, standard deviation, frequencies and percentages. Chi-square test was used to compare frequencies. Pearson's correlation test was used to assess the correlations. Level of significance of $\leq 0.05$ was considered as significant difference or correlation.

\section{Results}

Table (1) shows the highest percentage of the women subgroup are : women ages between (16-20) years old (50\% for study group and $40 \%$ for control group), those who live urban residents $(86.7 \%$ for study group and $73.3 \%$ for control group), those who are secondary school graduated (30\% for study groups) and primary school graduates ( $26.7 \%$ for control group), house wives (90\% for study group and $83.3 \%$ for control group) .

\section{Table (1) Statistical distribution of study sample} (women) by their demographic data

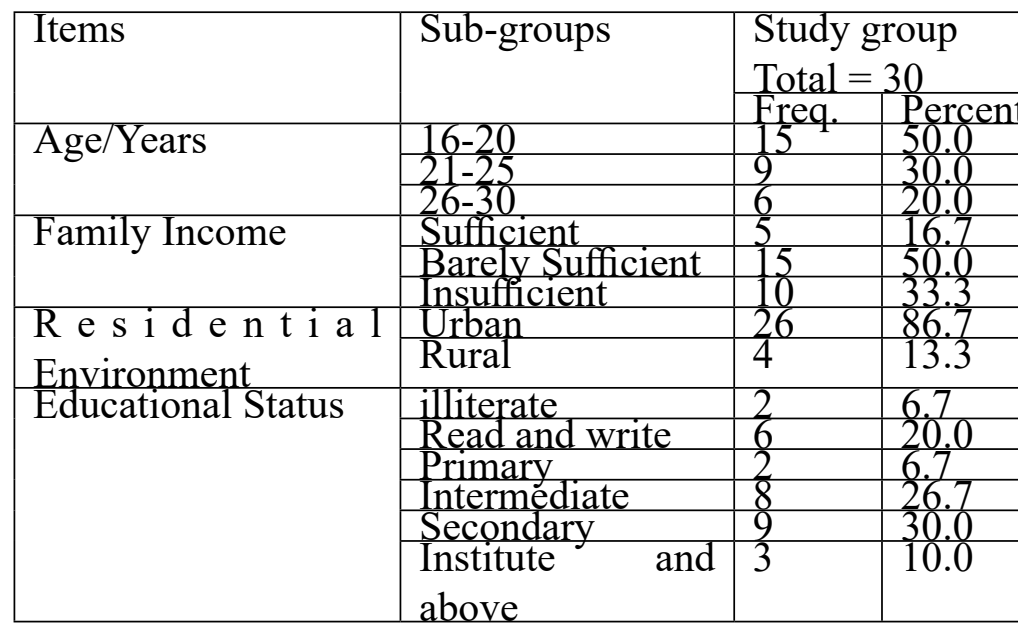

Table (2) reveals differences in the assessment in FLACC behavioral scale at different labor stages between study and control groups, it shows that there is no significant difference $(p>0.05)$ between study and control groups in the assessment in FLACC behavioral scale at the first active phase before applying the nonpharmacological pain managing interventions; regarding the other stages (active phase (after intervention); transition phase; second Phase; third Phase) which show a remarkably significant reduction pain according to in FLACC behavioral scale .

Table (2) Differences in the assessment in FLACC behavioral scale at different labor stages between study and control groups

\begin{tabular}{|c|c|c|c|c|}
\hline \multirow[t]{2}{*}{ Items } & \multirow[t]{2}{*}{ Sub-groups } & \multicolumn{2}{|c|}{$\begin{array}{l}\text { Study group } \\
\text { Total }=30\end{array}$} & \\
\hline & & Fr & $\%$ & \\
\hline Active phase & Relaxed and Comfort & 0 & 0.0 & \\
\hline ( B e fore & Moderate & 0 & $\frac{0.0}{13.3}$ & \\
\hline intervention) & Severe & 26 & 86.7 & \\
\hline$A c t i v e$ & Relaxed and Comfort & 0 & 0.0 & \\
\hline phase (After & Mild & $\frac{0}{23}$ & $\frac{0.0}{767}$ & \\
\hline intervention) & Severe & 7 & 10.1 & \\
\hline
\end{tabular}




\begin{tabular}{|l|l|l|l|}
\hline \multirow{3}{*}{$\begin{array}{l}\text { Transition } \\
\text { phase }\end{array}$} & Relaxed and Comfort & 0 & 0 \\
\cline { 2 - 4 } & Mild & 0 & 0 \\
\cline { 2 - 4 } & Moderate & 26 & 8 \\
\cline { 2 - 4 } & Severe & 4 & 1 \\
\hline \multirow{3}{*}{ S e c o n d } & Relaxed and Comfort & 0 & 0 \\
\cline { 2 - 4 } & Mild & 0 & 0 \\
\cline { 2 - 4 } & Moderate & 24 & 8 \\
\cline { 2 - 4 } & Severe & 6 & 2 \\
\end{tabular}

\section{Discussion}

The present study reveals that the highest percentage of the women subgroup are : women with ages between (16-20) years old (50\% for study group and $40 \%$ for control group) (table 1). This result is supported by Shresthawho indicated that labor pain was found to be more sever in younger age (adolescence parturient) as compared to those above $20^{(6)}$. In addition, these results study reported by Vyas, et.al who evaluated intra partum non-pharmacological pain relief techniques during labor, and found that out of the (60) sample of primigravida woman, the highest age groups were aged between (1822 ) years old and that was $(41.7 \%)$ and the lowest were found in the age group of (30-34) and they are accounted $(11.7 \%)^{(7)}$.

Concerning the level of education, the study reveals that the highest percentage of the study sample are secondary school graduated (30\% for study groups) and primary school graduates (26.7\% for control group), (table 1).

These result was in agreement with study conducted by Daniel, et al. who stated that the pain of a woman experiences during labor and birth is subjective, indivisaulized and caused by a number of interrelating factors such as physical, affective, psychological and environmental components all shape the pain experience. One of these factors is the educational level of women which majority of them (26.7\%) are primary school graduates $^{(8)}$.

The study results reveal that the highest percentage of the study sample are live urban residents $(86.7 \%$ for study group and $73.3 \%$ for control group). This is agreement with across-sectional survey on Iraqi woman that use of complementary and alternative medicine in pregnancy reported by Hwang et al. found that (53.7\%) of Iraqi woman Women Were living in urban areas ${ }^{(9)}$.

The study result reveals that the highest percentage of the study sample are barely sufficient family income (50\% for study group and $63.3 \%$ for control group) They are accounted through applying of the Ministry

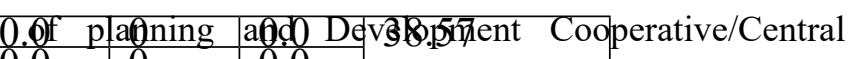
8. 6 tatistigal Orghnfation(0!(6ob)ique and Information

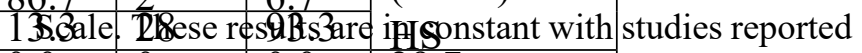

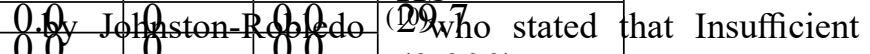
800 women were (e) 20 attend 27ildbitth? QeptersHSd classes and they are more likely to acquire information about childbirth from their mothers rather than acquired information from medical personnel during prenatal care visits. So that, these women experience higher levels of pain during childbirth. In addition, Al Ahmmar and Tarrafindicated, that the women with Sufficient of socioeconomic was more convinced with the labor process than those with Insufficient $^{(11)}$.

Table (2) show that reveals statistical distribution and difference in overall assessment of FLACC behavioral scale between study and control groups, it shows that there is no significant difference between study and control groups according to the evaluation of pain sings in term of FLACC behavioral scale; expect for face signs which indicated increased pain in the control group.

These finding are supported with a randomized controlled trial study in Turkey reported by Yuksel et al. ${ }^{(12)}$ which measured the effects of breathing exercises on maternal pain during the second stage of labor which revealed that the mean visual analog scale score of intervention the study group and control group were (88.+ $6.3)$ and $(90.5)+7.0)$, respectively $(p>0.001)$. based on this study, breathing exercises for women are effective in reducing the perception of labor pain; therefore breathing exercises consider an effective method pain management and lessening the duration of labor. The finding of the current study are supported with studied which used non-pharmacological pain relief method. A study reported in India by Jhala and its results show that practice of breathing exercise conditioned the mother to breathe and relax during contractions to control the experience of pain in gravid mothers, and shortens the duration of labor and prevents the complications during labor $^{(13)}$.

\section{Conclusions}

It is concluded that breathing has reduced pain during active phase, transition phase, and second phase.

Ethical Clearance: Taken from University of Kufa ethical committee. 


\section{Source of Funding: Self}

\section{Conflict of Interest: Nil}

\section{References}

1. Sercekus, p; Okumus, H. Fears associated with childbirth among nulliparous women in Turkey. Midwifery. 2009 : 155-162.

2. Gaskin, I.M. Ina May's Guide to childbirth: Update with New Material; Vermilion: London, UK, 2008.

3. Labor, S.; Maguire, S. The Pain of Labour. Rev Pain. 2008 : 15-19.

4. Sulima, M. Alternatywnemetodylagodzeniaboluporodowego. Eur. J. Med. Technol. 2013;1:3238.

5. Hall, H. G., Griffiths, D. L., \& McKenna, L. G. The use of complementary and alternative medicine by pregnant women: a literature review. Midwifery. 2011; 27(6): 817-824.

6. Shrestha, I., Pradhan, N., \& Sharma, J. Factors influencing perception of labor pain among parturient woman at Tribhuvan University teaching hospital . Nepal Journal of Obstetrics and Gynaecology. 2013; 8(1): 26-30.

7. Vakilinan, K., Davoud Abadi, M., \& Seyed Zadeh Aghdam, N. The Effects of Breathing Techniques on the Length of Labor Active Phase and its Second Stage in Women's First Labor. Complementary Medicine Journal of Faculty of Nursing \& Midwifery. 2014; 3(4) : 666-673.

8. Daniel, G., Oyetunde, M., \& Eleri, G. (). Mother's validation of midwives care in the management of labor pain in Plateau State, Nigeria. International Journal of Nursing and Midwifery,2015; 7(1) : 123 133.

9. Hwang, J. H., Kim, Y. R., Ahmed, M., Choi, S., AL-Hammadi, N. Q., Widad, N. M., \& Han, D. Use of complementary and alternative medicine in pregnancy: a cross-sectional on Iraqi women. BMC Complementary and Alternative Medicine.2016; 16(1) : 191.

10. Johnston-Robledo, I. Beyond Lamaze: Socioeconomic status and women's experiences with childbirth preparation. Journal of Gender, Culture and Health. 1998; 3(3): 159-169.

11. Kamalifard, M., Shahnazi, M., Melli, M.S., Allahverdizadeh, S., Toraby, S., \& Ghahvechi, A. The efficacy of massage therapy and breathing techniques on pain intensity and physiological responses to labor pain. Journal of Caring Sciences. 2012; 1(2) : 73.

12. Yuksel, H., Cayir, Y., Kosan, Z., \& Tastan, K. Effectiveness of breathing exercises during the second stage of labor on pain and duration: a randomized controlled trail. Journal of integrative medicine. 2017; 15 (6) : 456-461.

13. Jhala A. A study to assess the effectiveness of Lamaze breathing on labor pain and anxiety towards labor outcome among primigravida mothers during labor in community health center, Kolar Road, Bhopal (M.P.);Indian Journal of Obstetrics and Gynecology. 2017; 5(1) : 19-22. 